\section{The Role of Mental Rotation in Letter Processing by Children and Adults*}

JENNIFER M. YOUNG AND

SANDRA R. PALEF

Ontario Institute for Studies in Education, University of Toronto

GORDON D. LOGAN

Erindale College, University of Toronto

\section{ABSTRACT}

Children and adults identified or discriminated the version (normal or backwards) of letters presented in 10 different orientations between o and 180 degrees. Reaction time to discriminate version increased linearly with orientation for both children and adults, but reaction time to identify was not strongly influenced by orientation for either children or adults. This suggests that both children and adults mentally rotate a representation of the letter to discriminate version, but that neither children nor adults rotate letters to identify them.

Mental rotation is an important skill that children and adults can use to deal with misoriented stimuli (Cooper \& Shepard, 1973; Marmor, 1975, 1977). For example, in a version task in which subjects must judge whether or not a character is presented in a normal (e.g., R) or backwards (e.g., Я) version, subjects apparently rotate misoriented characters (e.g., $y$ ) to the upright position before making the judgment (Cooper \& Shepard, 1973). Mental rotation is characterized by a linear relation between reaction time and the angle through which the mental representation is rotated, indicating a continuous transformation that is executed at a constant rate (Shepard \&
Metzler, 1971). It is apparent from the literature that rotation rate increases with age from childhood to adulthood (see Table II); our experiment focuses on two other issues on which children and adults might differ.

First, it is apparent that adults do not need to rotate alphanumeric characters to identify them (Corballis \& Nagourney, 1978; Corballis, Zbrodoff, Shetzer \& Butler, 1978), despite claims that some knowledge about orientation must be available before identity can be established (Rock, 1974). The evidence against rotation is that the effect of orientation in the identification task is substantially smaller than that observed in a version task believed to require rotation (Cooper \& Shepard, 1973). This finding may reflect the extensive practice adults have had with alphanumeric characters, and may not replicate with children. That is, mental rotation may be a more general strategy in children than in adults, and in particular, children might be expected to rotate letters (which are relatively unfamiliar) to identify them.

Second, even in the version task, which has provided much of the evidence for mental rotation, it is apparent that adults do not rotate stimuli in all orientations. The function relating reaction time to orientation typically has a quadratic component, reflecting a range from o to about 60 degrees in which reaction time is independent of orientation, followed by a range from 80 to 180 degrees in which reaction time increases linearly with orientation (Cooper \& Shepard, 1973; Hock \& Tromley, 1978). The range from o to 60 degrees reflects a range of 'perceptual uprightness' which adults have presumably developed from extensive experience with alphanumeric characters. Because children have had less experience, they might be expected to have

\footnotetext{
*This work was supported by a Canadian Commonwealth scholarship to the first author and by Grant 410-77-0797 from the Humanities and Social Sciences Research Council of Canada to the second author. Requests for reprints should be sent to Jennifer M. Young, Department of Applied Psychology, orse, 252 Bloor St West, Toronto, Ontario, $\mathrm{M}_{5} \mathrm{~S}_{1} \mathrm{~V} 6$.
} 
a narrower range of perceptual uprightness than adults. The existing literature provides some evidence on this issue: Marmor $(1975,1977)$ found no evidence of a quadratic component in children from 4.5 to 8.6 years old, whereas Childs and Polich (1979) found such trends in children 9.25 and 11.08 years old. However, Marmor used pictures of bears and cones instead of the alphanumeric stimuli used by Childs and Polich, Hock and Tromley, and Cooper and Shepard, and it is possible that her pictures were not sufficiently familiar to produce the perceptual uprightness effect; indeed she found no such effect in adults with these pictures. Thus, the existing literature may overestimate the age at which the perceptual uprightness effect first appears.

To test these notions, we administered version and identification tasks to children and adults using alphanumeric stimuli for both tasks. Since the version task is generally believed to involve rotation, it provides a standard against which performance on the identification task can be evaluated; if identification requires rotation, the slope of the orientation function must be at least as steep as the one observed in the version task. Moreover, the alphanumeric stimuli allow a clearer assessment of the perceptual uprightness effect than do Marmor's stimuli. The critical questions are first, whether children's letter identification involves mental rotation; and second, whether the range of perceptual uprightness in children is as broad as that for adults.

\section{METHOD}

\section{Subjects}

Subjects were 12 Grade 2 children (mean age $=$ 7.6 yrs) and 12 undergraduates. Six adults and six children were randomly assigned to each of the two tasks.

\section{Apparatus and Stimuli}

The stimuli were uppercase letters F, G, J, and $\mathbf{R}$, made up from Helvetica medium letraset, presented in two versions (normal or backwards) and in ten angular orientations ranging from $o$ to 180 degrees in 20-degree steps. Altogether 80 different stimuli were produced ${ }_{4}$ letters $x_{2}$ versions $\times 10$ orientations) and each was used four times to make a set of 320 experimental stimuli. The letters were rear-projected onto a circular screen by a projection tachistoscope, and subtended a visual angle of about $1.58 \mathrm{de}-$ grees.

Each trial consisted of a 500 msec warning tone, a 500 msec delay, and the presentation of a slide for 2 seconds. Reaction time was measured from the onset of the slide to the pressing of a response key.

\section{Procedure}

In the version task, children and adults were told they would see a single letter presented on the screen in various orientations, and that their task was to indicate whether the letter was 'normal' or 'backwards' by pressing one of two response buttons. Examples were shown and care was taken to ensure that all subjects understood the task.

In the identification task, the stimuli were described to the subjects as above, but they were told that their task was to identify the letter presented on each trial by pressing one of four buttons, each of which was assigned to a different letter.

In both tasks, subjects were instructed to respond as quickly and as accurately as possible with the index finger of their preferred hand. They were told to rest their responding finger between trials on a spot equidistant from the four response buttons.

Both tasks involved 320 trials broken into four blocks of 80 trials each. Children served in four sessions, each consisting of a block of 80 trials with a break in the middle. Adults completed all four blocks in one session with a break after every 40 slides. The order in which the stimuli were presented was counterbalanced across subjects.

\section{RESULTS}

The first ten reaction times for each subject were treated as practice and discarded from the analysis. The average error rate on the version task was $9.7 \%$ for children and $7.7 \%$ for adults. On the identification task it was $1.2 \%$ for children and $.9 \%$ for adults. Mean reaction times for correct decisions by children and adults in each task are presented in Figure 1. These mean reaction times were subjected to a five-way analysis of variance (age $\times$ task $\times$ letter $\times$ 


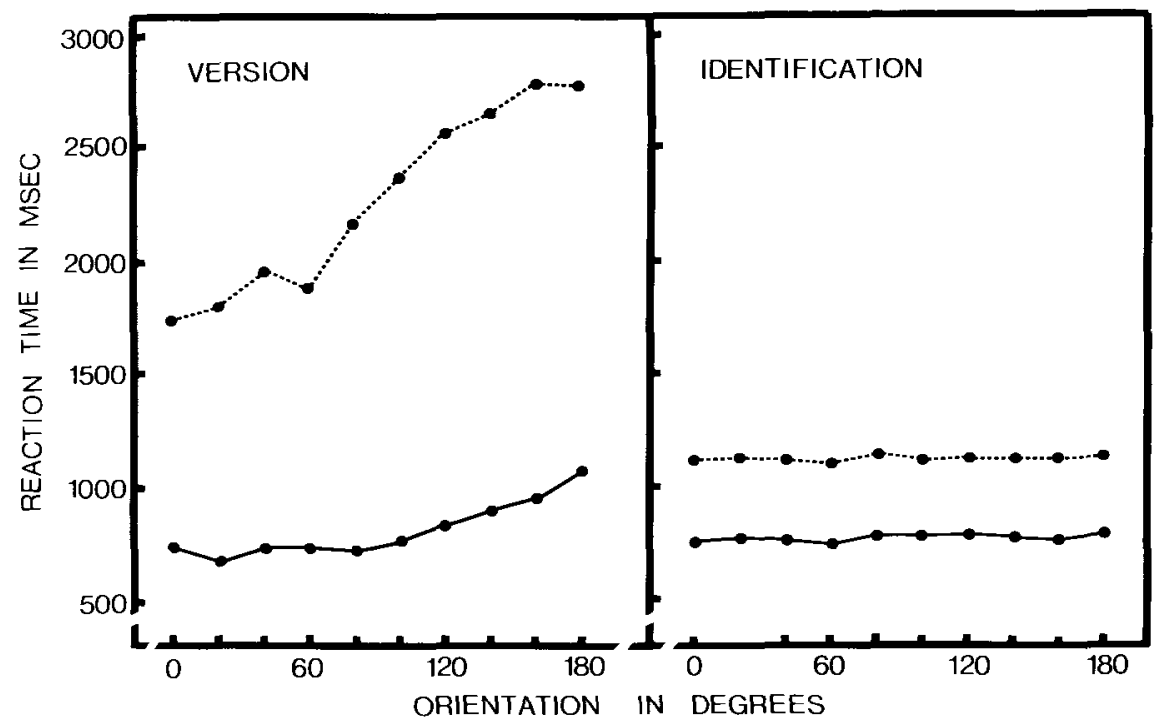

FIGLRE 1 Mean reaction times as a function of angular orientation for the version (left panel) and identification (right panel) tasks by children (broken line) and adults (solid line).

orientation $\times$ version). There was a main effect due to task $F(1,20)=10.83, p<.01$ and to age $F(1,20)=24.78, p<.001$. Latencies for the version task were slower than those for the identification task, and children were slower overall than adults. There was a significant main effect due to angular orientation, $F(9,180)=16.32, p<$ .001 , and significant interactions between task and orientation, $F(9,180)=15 \cdot 32, p<$ .001 , between age and orientation, $F(9$, $180)=5.30, p<.001$, and between task, age, and orientation, $F(9,180)=5.62, p<$ .01 . The meaning of these effects can be seen most clearly in trend analyses which were performed to determine the form and steepness of the four orientation functions.

For children doing the version task, reaction time increased linearly as a function of orientation, $F(1.45)=88.13, p<.001$ and this trend accounted for $95 \%$ of the variance. There was no significant quadratic trend. The slope of the regression line was $6.56 \mathrm{msec} / \mathrm{deg}$, indicating that children were mentally rotating at $15^{2} \mathrm{deg} / \mathrm{sec}$. For adults doing the version task there was both a significant linear trend $F(1,45)=189.54$, $p<.001$ which accounted for $80 \%$ of the variance, and a significant quadratic trend
$F(1,45)=44.86, p<.001$ which accounted for a further $19 \%$ of the variance. The significance of the quadratic trend suggests that adults did not need to mentally rotate misoriented letters to make version decisions about them unless they were tilted more than about 60 degrees from the upright. To assess this more directly, two regression lines were fitted to the data. The first, between o and 60 degrees, had a slope of . $10 \mathrm{msec} / \mathrm{deg}$ and accounted for only $1 \%$ of the variance, indicating that mental rotation was not required. The second, between 80 and 180 degrees, had a slope of 3.40 msec/deg and accounted for $97 \%$ of the variance. This indicates that adults were mentally rotating at $294 \mathrm{deg} / \mathrm{sec}$, twice as fast as children.

These effects were also apparent for each letter. The $F$-ratios for linear and quadratic trends for each letter are presented in Table I. These data show that for children, the linear trends were significant for each letter, but the quadratic trends were not, while for adults, both the linear and quadratic trends were significant for each letter.

In the identification task there were no significant trends for children. For the 


\begin{tabular}{llcccc}
\hline Subjects & Trend & $F$ & $G$ & $J$ & $R$ \\
\hline Children & Linear & $62.76^{*}$ & $103.79^{*}$ & $48.91^{*}$ & $154.99^{*}$ \\
& Quadratic & 0.03 & 0.83 & 1.64 & 0.15 \\
Adults & Linear & $159.68^{*}$ & $201.58^{*}$ & $276.75^{*}$ & $133.93^{*}$ \\
& Quadratic & $42.97^{*}$ & $71.17^{*}$ & $37.90^{*}$ & $30.69^{*}$ \\
\hline
\end{tabular}

${ }^{*} p<.001(d f=1,45)$.

adults there was a marginally significant linear trend $F(1,45)=5.47, p<.05$, which accounted for only $18 \%$ of the variance. Since the slope of this regression line was the same as that for orientations between $o$ and 60 degrees for adults on the version task, a mental rotation explanation can be effectively ruled out.

\section{DISCUSSION}

The results show that children mentally rotate letters to decide version, just as adults do, but at a slower rate. The rates of rotation with adults and 7.6-year-olds agree well with the developmental increase in rotation apparent in studies comparing adults with children 4.5 to 8.5 years old (Marmor, 1975, 1977; see Table II). Recent evidence of no interaction between age and orientation, comparing adults with $9^{-}$and 11-year-olds, suggests that the developmental increase in rate of rotation may be complete by age 9 (Childs \& Polich, 1979). These data are not included in Table in because Childs and Polich did not report the appropriate regression equations.

In the present study, an appreciable range of perceptual uprightness was apparent only in adults. Again, this is consistent with published data; the youngest children to show quadratic trends in the orientation function (from o to 180 degrees) were the 9-year-olds in the Childs and Polich study (1979). Our findings with alphanumeric stimuli suggest that Marmor's (1975, 1977) failure to find a quadratic trend with younger children was not due to stimulus differences.
TABLE II

Rotation rates as a function of age in published data and the present study (rates are averages from regression equations except where indicated)

\begin{tabular}{lll}
\hline $\begin{array}{l}\text { Age } \\
(y r s)\end{array}$ & $\begin{array}{l}\text { Rotation rate } \\
(d e g / s e c)\end{array}$ & Study \\
\hline 4.5 & 37 & Marmor, 1977 \\
5.5 & 84 & Marmor, 1977 \\
5.7 & 67 & Marmor, 1975 \\
7.6 & 152 & The present study \\
8.6 & 167 & Marmor, 1975 \\
Adults & 240 & Marmor, 1977 \\
Adults & 294 & The present study \\
Adults & 220 (mean) & Cooper \& Shepard, 1973 \\
Adults & $160-800$ (range) & Cooper \& Shepard, 1973 \\
\hline
\end{tabular}

Our analysis of individual letters in the adult data is consistent with Hock and Tromley's (1978) except for our finding of a significant quadratic trend for the letter G. However, Hock and Tromley deliberately used a stylized (i.e., nearly circular) capital $G$ that had no obvious top or bottom to reduce the impression of perceptual uprightness. Our capital $\mathrm{G}$ was made from a more normal typeface, in which top and bottom were perhaps more obvious, so the impression of perceptual uprightness may have been stronger.

Perhaps the most important result in the present study was the failure to find orientation effects in the identification task. This suggests that neither children nor adults need to rotate mentally in order to identify misoriented letters. Presumably, the features critical to identification are extracted independent of the orientation of the letter. This finding, together with the results with adults (also see Corballis \& 
Nagourney, 1978; Corballis et al., 1978), suggests that a mental rotation strategy may be used in a narrower range of situations than had previously been thought.

\section{RESUME}

Des enfants et des adultes ont à identifier des lettres présentées en 10 orientations différentes (de o à $180^{\circ}$ ) ou à décider si l'orientation des lettres présentées est normale ou inversée. Les résultats montrent que le temps de réaction, dans la première tâche, n'est pas fortement influencé par l'orientation ni chez les enfants, ni chez les adultes, mais que ce temps de réaction, dans la seconde tâche, augmente de façon linéaire avec l'orientation aussi bien chez les enfants que chez les adultes. Ces données suggèrent que les enfants et les adultes effectuent une rotation mentale de la lettre présentée, pour décider de son orientation, mais que ni les uns ni les autres n'effectuent cette rotation pour identifier la lettre.

\section{REFERENCES}

CHILDS, M.K., \& POLICH,J.M. Developmental differences in mental rotation. $J$. exp. child Psychol., 1979 27, 339-351
COOPER, L.A., \& SHEPARD, R.N. Chronometric studies of the rotation of mental images. In w.G. CHASE (Ed.), Visual information processing. New York: Academic, 1973

CORBAllis, M.C., \& NAgourney, B.A. Latency to categorize alphanumeric characters as letters or digits. Canad.J.Psychol., 1978, 32, 186-188

CORBALIIS, M.C., ZBRODOFF, N.J., SHETZER, L.I., \& BUTLER, P.B. Decisions about identity and orientation of rotated letters and digits. Mem. Cognit., 1978 , $6,9^{8}-107$

HOCK, H.S., \& TROMLEY, C. Mental rotation and perceptual uprightness. Percept. Psychophys., 1978, 24, 529533

MARMOR, G.s. Development of kinetic images: When does the child first represent movement in mental images? Cognit. Psychol., 1975, 7, 548-559

MARMOR, G.S. Mental rotation and number conservation: are they related? Develop. Psychol., 1977, 13, $320-325$

ROCK, 1 . The perception of disoriented figures, $\mathrm{Sci}$. $A m ., 1974$, 230, $78-85$

SHEPARD, R.N., \& METZL.ER, J. Mental rotation of threedimensional objects. Science, 1971 , $171,701-703$

(Date accepted 8 January 1980 ) 